\title{
A HIERARCHICAL MODEL FOR E-LEARNING IMPLEMENTATION CHALLENGES USING AHP
}

\author{
ShahidFarid $^{1}$, Rodina Ahmad ${ }^{2}$, MujahidAlam ${ }^{3}$ \\ ${ }^{1,2}$ Department of Software Engineering, Faculty of Computer Science and Information Technology, University of \\ Malaya, Kuala Lumpur, Malaysia. \\ ${ }^{3}$ Informatics Complex (ICCC), Sector H-8, Islamabad, Pakistan. \\ Email: ${ }^{1}$ shahidfarid@siswa.um.edu.my, ${ }^{2}$ rodina@um.edu.my, ${ }^{3}$ mujahidalam@gmail.com
}

\begin{abstract}
E-learning is becoming the new paradigm of learning and training, especially in Higher Educational Institutions (HEIs) around the globe. HEIs in developing countries are struggling to shift to this new paradigm that would facilitate accommodating increasingly more learners in their own places and with their own time constraint choices. E-learning is not gaining as much attention in developing countries as anticipated in the last decade. Moreover, very little work has been done in this area of research in developing countries like Pakistan. This study contributes to formulating a hierarchical model of the challenges affecting the integration of information and communication technology in Pakistan's HEIs. This study also contributes devised strategies and recommendations to overcome challenges by providing a roadmap for the implementation of e-learning systems in developing countries. An empirical-based research method was employed, with two surveys conducted on e-learning experts from different public universities. The factor analysis method was used to categorize challenges, while the Analytical Hierarchy Process (AHP) method was utilized to prioritize the identified challenges. The findings revealed 17 critical challenges, which were then categorized into 5 dimensions. The study's implications in terms of research and practice, limitations and future research directions are also discussed.
\end{abstract}

Keywords:E-learning challenges; distance education and tele-learning; distributed learning environments; lifelong learning; Analytical Hierarchy Process.

\subsection{INTRODUCTION}

The use of the Internet as well as Information and Communication Technology (ICT) for education and training purposes has valuable weightage as suggested in the existing literatures[1-5]. The focus of education and training has shifted from traditional modes (e.g. postal services) to electronic-based high-speed digital communication. Researchers refer this new paradigm with various synonyms like borderless learning [6], Internet-based learning [1, 7], flexible learning, web-based learning, online learning, technology-based learning, electronic learning or elearning [2, 8-11]. This mode of learning can improve the quality of teaching and learning [5]. The e-learning market exhibits a growth rate of $35.6 \%$ worldwide [12]. For this reason, HEIs worldwide are switching to this borderless learning approach to reduce the cost of education and particularly to increase their revenue.

E-learning is still in the early stages of adoption and implementation in most developing countries. Nonetheless, many of them, including Pakistan are eager to implement e-learning [13], although faced with challenges not normally faced by developed countries, such as infrastructure, Internet access, resources, institutional support, personal characteristics, well as policies and cultural constraints[5, 14]. In the current economic scenario of Pakistan, e-learning seems to offer one of the best possible solutions to educating people. In Pakistan, E-learning seems to not have gained as much attention as predicted earlier[15]. Some studies, e.g.[14, 16-20]have been 
conducted to identify the e-learning issues and challenges faced by HEIs in Pakistan. However, minimal effort has been made to either formulate strategic steps or develop models to prioritize or rank the challenges, so that those challenges can be addressed in a more systematic way. Therefore, this study focuses on the identification, thorough evaluation, and prioritization of e-learning implementation challenges, according to their importance and relevancy in particular dimensions, such as personal, institutional, technical, administration and software, for e-learning implementation. The dimensions have already been identified in our previouswork [20], where sixteen issues were revealed from qualitative investigation. However, in the present work, we employ a quantitative survey investigation to determine a more comprehensive set of challenges from experts and practitioners from the e-learning community. This study contributes towards the formulation of a hierarchical model for the challenges influencingthe integration of information and communication technology in HEIs in Pakistan. Moreover, this study also devises a roadmap to further understand the challenges for more successful implementation of e-learning in developing countries. Furthermore, we employ the Analytical Hierarchy Process (AHP) technique to ensure precise prioritization of the identified challenges, so that HEIs and the responsible government authorities may address the challenges with respect to their priorities.

This paper is organized as follows. Section2 presents a background of e-learning in the context of Pakistan. Section3 describes our research design along with the data analysis tools utilized. The results obtained from empirical investigations are discussed in Section4, while hierarchal model formulation along with the current study implications and limitations are discussed in Section5. Finally, Section6 expresses the conclusions and potential future directions of this work.

\subsection{BACKGROUND}

From the end of World War II, the gapsin living standard, socio-economic system, food and educational opportunities between developed and developing countries widened[21]. The intense use of ICT in the education sectors of developed countries alleviated the establishment of completely ICT-based universities called virtual universities. Moreover, numerous world-leading universities are becoming "dual mode universities" by offering courses to learners in traditional ways as well as through the use of ICT [22]. According to the policy statements of international agencies (UNESCO, World Bank, European Commission, etc.) open and distance learning have been gaining popularity since 1990 [16, 23]. In developing countries, ICT has not penetrated to a higher extent in many HEIs due to numerous socio-economic and technological constraints[24].

Many countries are taking advantage of ICT in changing their ways of delivering education [25]. Nevertheless, HEIs of developing countries are facing numerous challenges in implementing and promoting e-learning,as well as the dedication and devotion needed to overcome these challenges. Among the challenges is the lack of skilled teachers, educational infrastructure and technology access to enhance education at different levels[14, 17]. E-learning systems encompass many stakeholders, including learners/users, instructors/faculty, institutions, administration, software developers, instructional designers, managers, online facilitators, multi-media designers, and learning object developers [3, 9, 26, 27]. According to Majdi[3] the most important views (stakeholders) of an e-learning system are of users, managers and software developers. However, Selim[9]states that there are four major stakeholders of elearning in HEIs, namely learners, instructors, institutions and administrations. Hence, challenges vary from one stakeholder to another as each has their own views and needs regarding issues and challenges in the implementation of an e-learning system. 


\subsection{E-learning in Pakistan}

Many countries are integrating ICT in education to enhance students' learning experience [25]. This drift is easily perceived in Pakistan, especially since the last decade when the country started experiencing a rapid growth of ICT infrastructure. The Government of Pakistan (GOP) has been profound in creating IT infrastructure and boosting digital learning in the country.For this purpose, in 2002, a university has been established with the name of the Virtual University (VU) of Pakistan and later in 2007 the National ICT R\&D Fund for ICT-based learning and training has also been founded [28]. Still,a number of socio-economic, cultural and technological constraints are hindering theachievement of higher literacy rates in the country [15]. Pakistan has developed its "ICT in Education Master Plan", in 2007, that defines strategies to integrate ICT for the expansion of educational opportunities, improvements of student learning and developing capacity at various levels[29]. However, the GOP is still attempting to achieve its target of "education for all". As such, it is essential to identify the critical challenges of elearning so that the goal of the GOP may be achieved. Moreover, the identified challenges also require categorization and prioritization in order for a paradigm shift from a conventional educational system to this new ICT mediated education model to become possible.

Allama Iqbal Open University (AIOU), Islamabad, Pakistan, is one of the world's mega universities that provide education through the distance learning paradigm. It is the first distance learning university of Pakistan established in early 1974. With the explosion of ICT, AIOU is also changing its mode of learning to facilitate learners as much as possible. A center for instructional design has been established at AIOU, so as to develop localized Learning Objects (LOs) to assist local students. LO can be defined as an entity in electronic form, be it through audio, video, text, or power point presentations etc.,and it may also be recognized as a pedagogical entity [30]. These LOs are stored in learning repositories and learners can access them via telecommunication technologies [31]. Guler[32], states that LOrefers to reusable and digital resource with the aim of achieving learning purposes. In [33], LO is referred as Multimedia information, which is a collective set of content including text, animation, audio, video or images. Other HEIs are also eager to adopt this new paradigm of learning following AIOU. However, they face numerous challenges including cultural, economic, political, social, establishment costs, shortages of skilled personnel and deficiency of funds to establish new educational institutions in remote areas for delivering education to the people of Pakistan. In order to cope with these issues, establishmentof environment that would facilitate learners in their own places at minimum cost is needed, withthe only solution being to adopt e-learning.

Limited work is reported in the literature regarding the existing studies on identifying the problems faced by HEIs in Pakistan this field of study. Siddiqui[34],attempted to identify some of the concerns including technological and institutional infrastructure, computer literacy, English competency, lack of awareness, teacher training and interaction between students and teachers.In [16],several issues were identified, such as teacher training, electric power, ICT infrastructure, student assessment and insufficient funding, but the research is limited to only a single public university with no further discussion carried out in their study. Another effort was reportedin[35], highlighting the predictors of e-learning success. The authors focused on user satisfaction and discovered that lack of user training, underestimation, lack of awareness, lack of technical and administrative end-user support and resistance to change are among users' problems with e-learning. Moreover, their study is limited to only one province of Pakistan, NWFP (now called Khyber Pakhtunkhwa or KPK). Additionally, Qureshi [17]attempted and identified technical difficulties such as computer literacy, computer access, security and privacy, face-to-face interaction, English competency and students' resistance to change as some of the challenges ine-learning implementation. Their study emphasized and was limited to only one private sector university rather considering other HEIs in Pakistan. Moreover, the authors stressed on the implementation level rather than promoting e-learning. A number of e-learning issues related to developing countries like Pakistan were identified in[14]. These issues include lack of user perception, ineffective user training, borrowed e-learning models, digital divide and lack of technical support. Various e-learning challenges, for instance lack of knowledge about technology, usage problems and accessibility to e-learning tools were identified in[18] by conducting a survey in public sector universities in Pakistan. 
However, state-of-the-art research lacks in stressing the innumerable challenges (in Pakistani settings) regarding the implementation and promotion of e-learning. Furthermore, no attempt has been made to present a hierarchal model, which is crucial for the implementation of e-learning. Hence, we propose a hierarchical model that subsequently guides HEIs and HECs in revising their policies necessary for the implementation of e-learning in the country. To achieve our objectives (as discussed in section 1), the following research questions are formulated in the context of HEIs in Pakistan.

RQ1: What are the current challenges with the implementation of e-learning? (Identification)

RQ2: What are the general classifications of the identified challenges? (Categorization)

RQ3: Which challenges are most crucial to the implementation of e-learning? (Prioritization)

\subsection{RESEARCH DESIGN}

\subsection{Samples}

The samples selected for this study are experts with at least five years of experience in three major fields of elearning, namely academia, administration and software development. Utmost care was taken in selecting these experts. The academia and e-learning administration experts were selected from six identified public sector universities in Pakistan, which are dual mode universities. The software development experts were selected from the industry with experience in developing various e-learning products. The major stakeholders of this study are illustrated in Fig. 1.

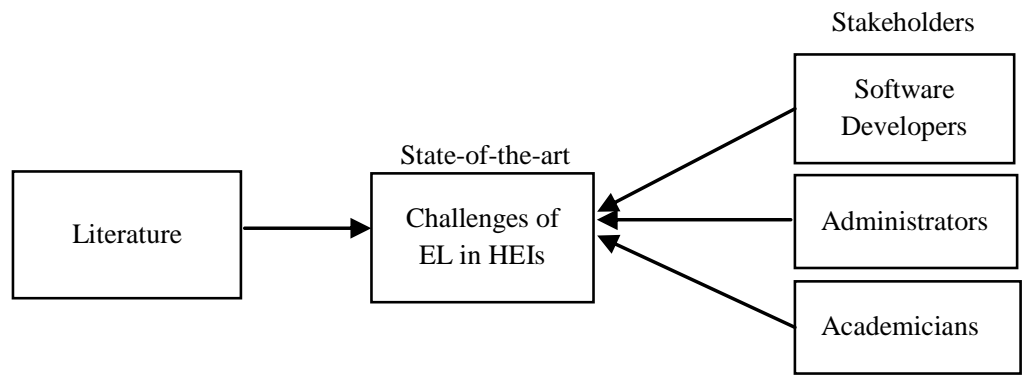

Fig. 1: Data gathering sources 
The sample size for this study is52 experts. It is important to highlight that all participants hold senior positions in their organizations with average experience of seven years (as mentioned in Table 1). These experts are playing crucial roles in the existing e-learning environment of their institutions. Table 1 tabulates the respondents' demographic details.

Table 1: Demographic profile of participants

\begin{tabular}{ccc}
\hline \multicolumn{1}{c}{ Demographic } & Frequency & Percent \\
\hline Gender: & 39 & 75 \\
Male & 13 & 25 \\
Female & & 06 \\
Age: & 03 & 25 \\
a) $21-30$ & 13 & 27 \\
b) $31-40$ & 14 & 32 \\
c) $41-50$ & 17 & 10 \\
d) $51-60$ & 05 & \\
e) Over 60 & & 17 \\
Qualification: & 09 & 33 \\
a) Bachelor & 17 & 50 \\
b) Masters & 26 & \\
c) Doctorate & & 42 \\
Area: & 22 & 21 \\
a) Academia \& Research & 11 & 31 \\
b) Administration & 16 & 06 \\
c) Software Development & 03 & 7 years \\
d) Both a \& b & & \\
Average Experience & & \\
\hline
\end{tabular}

\subsection{Data Gathering}

To identify state-of-the-art e-learning challenges, we categorized e-learning challenges into five major dimensions based on the experiences, observations and opinions of researchers from existing literature [3, 9, 20, 26, 27]. Five dimensions of e-learning challenges are software, technical, institutional, personal and cultural. These dimensions are illustrated in Fig. 2. An open-ended list of potential challenges and perceived dimensions was formulated after reviewing more than 50 published research papers, articles, case studies from various well-renowned journals and conferences. The open-ended survey is considered less bias than its counterpart, which may limit experts' opinion [36]. Before conducting the survey, a pilot test was performed not only to check the validity and reliability of the survey instrument but also to minimize the researchers' bias regarding the categorization of e-learning challenges. This pilot test was conducted with four e-learning experts having minimum five years of experience (one expert from each field of e-learning, i.e. academia, research, administration and software development). The questionnaire was altered by adding some additional challenges on the basis of input from experts. Some differences were also observed regarding the inclusion of challenges in the respective dimensions. This process was repeated twice to overcome disagreements between experts' opinions on including and excluding different issues or challenges among different dimensions. 


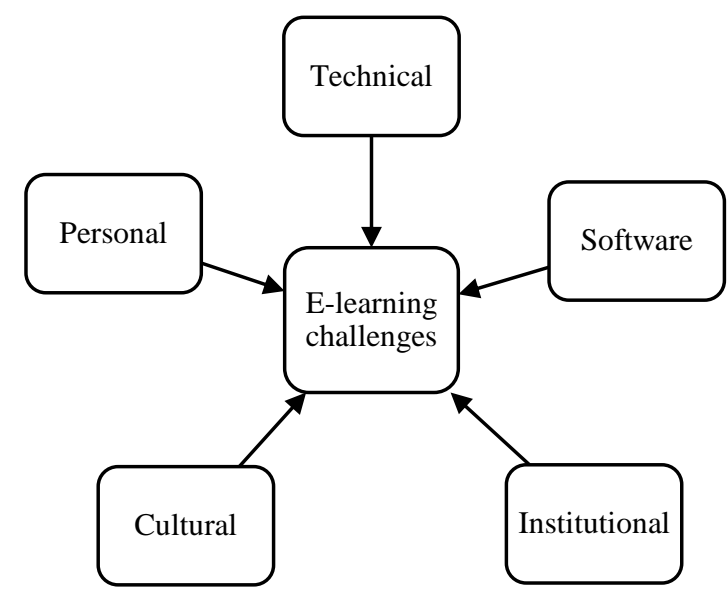

Fig. 2: Categories of e-learning challenges

\subsection{Data Analysis}

In order to find answers to RQ1, the objective is to identify the challenges influencing the implementation of elearning. Twenty-six challenges were identified (as summarized in Table 2), which are greater than those reported in [20]. These challenges were filtered with respect to importance according to the localized environment. In this study, a hierarchical model was formulated with seventeen challenges categorized into five dimensions followed by an empirical study to find the answerstothe second research question RQ2. In order to obtain answers to research question RQ3, the identified challenges were ranked with respect to their importance for the localized environment. For this purpose, AHP was deployed on the survey responses conducted among e-learning experts. Local and global ranks along with the respective challenge weights are discussed in Section 4 and illustrated in Tables 6 and 7 respectively. Details of the proposed model are discussed in section 5 and illustrated in Fig. 4.

\subsection{Research Tools}

This study employed the factor analysis method to filter an exhaustive list of e-learning challenges.For prioritization purposes, the analytical hierarchy process method was deployed. It is understood that the process of pair-wise comparison can be difficult and time consuming if the number of factors (challenges in this study) is large. Hence, in order to overcome this problem, factor analysis, cut-off-value or some similar method is required to reduce the number of factors. 
Table 2: Identified e-learning challenges

\begin{tabular}{lll}
\hline No. & \multicolumn{1}{c}{ Challenges } & \multicolumn{1}{c}{ Literature } \\
\hline 1. & Lack of instructional designers & {$[37],[38]$} \\
2. & Lack of instructional design processes & {$[39]$} \\
3. & Lack of software quality assurance processes & {$[40],[41]$} \\
4. & Bandwidth & {$[42],[43]$} \\
5. & Lack of formal implementation processes & {$[44],[45],[19],[46]$,} \\
6. & Lack of faculty interest & {$[11],[45],[19]$} \\
7. & Lack of ICT enabled teachers & {$[47],[48],[34],[45],[38],[49]$,} \\
8. & Lack of ICT enabled students & {$[50]$} \\
9. & Power failure & {$[51],[45],[38],[19],[17]$} \\
10. & Lack of LOs in the local language & {$[52],[44],[16],[17]$} \\
11. & Socio-Cultural Norms & {$[53],[30],[38],[17]$} \\
12. & Lack of resources & {$[16]$} \\
13. & Accessibility to Internet broadband & {$[53],[16]$} \\
14. & Access to the latest computers & {$[38],[18]$} \\
15. & Borrowed e-learning models & {$[53],[38],[17]$,} \\
16. & Lack of leadership & {$[14],[54]$} \\
17. & Change in university structure & {$[45]$} \\
18. & E-learning environment & {$[55],[56],[45]$} \\
19. & Software interface design & {$[45]$} \\
20. & Support for students & {$[57]$} \\
21. & Support for teachers & {$[57]$} \\
22. & Role of teachers and students & {$[57]$} \\
23. & Learning style & {$[53]$} \\
24. & Cost of mobile Internet & {$[53]$} \\
25. & Practical arrangements for practical oriented courses & {$[20]$} \\
26. & Literacy rate & {$[20]$} \\
& & \\
\hline & &
\end{tabular}

\subsubsection{Filtering the Potential Challenges}

Factor analysis is a data reduction technique that takes large sets of variables (challenge in this study) and reduces them using a smaller set of components or factors [58]. The method of reducing data or filtering the factors is commonly used in research in various disciplines like psychology, telecommunication and education and is considered the method of choice for interpreting self-reported questionnaires [59, 60]. These factors are assumed to represent dimensions within the datasets [61]. Numerous variations in the factor analysis method can easily be perceived from the literature $[60,62]$.

The experts sampled for this study were requested to rate the challenges in each dimension using a five-point Likert scale from unimportant $(=1)$ to most important $(=5)$. The participants were further requested to add any critical issue or challenge to the appropriate dimension, which in their opinion is missing but is crucial to the localized environment. Once the experts completed the survey, the survey instruments were obtained for further analysis to filter the relevant challenges through a process similar to that in[60]. 43 responses were received, for a response rate of $82 \%$. Data was analyzed using spreadsheet software in terms of percentage and mean values, which revealed seventeen challenges. A scale value was assigned to each of the five responses as follows: 


\begin{tabular}{lc} 
Level of Agreement & Scale Values \\
\hline Most Important (MI) & 5 \\
Important (I) & 4 \\
Neutral (N) & 3 \\
Least Important (LI) & 2 \\
Un-Important (UI) & 1
\end{tabular}

\subsubsection{Analytical Hierarchy Process (AHP)}

Several methods can be utilized to categorize e-learning challenges such as multivariate or multi-criteria techniques However, these techniques do not integrate the decision maker's preference structure[63]. On the other hand, Analytical Hierarchy Process (AHP) method helps decision makers or managers in a waysuch that managers are able to express their individual preferences or priorities [64]. However, this methodology is more suitable when the decision maker has no clear preferences over the diverse elements [65].

\section{a) Overview}

AHP was proposed by Saaty[66, 67], is a powerful and flexible process used to make decisionsin order to develop priorities amongst different attributes. It allows decision makers to intuitively evaluate the relative weights of multiple criteria (or multiple options) against given criteria. It helps decision makers with both qualitative and quantitative data for decision making, as the decision makers can easily distinguish which criterion is more important than others. The decision makers perform simple pairwise comparison judgments (A is more important than B) as theybecome comfortable using a pairwise comparison form of input data. Saaty[66, 67], developed a reliable method of transforming such pairwise comparisons into sets of numbers expressing the relative priority of each criteria. AHP has broadlyreflected the importance or weight of each component (criterion) associated with priorities [68, 69]. Moreover, the AHP technique as a decision-making tool can accommodate model revisions and simulations through sensitivity analysis $[64,70,71]$. The success of AHP as a practical and reliable method is highlighted by its extensive application in the past two decades [72].

The AHP technique has the unique advantage of building hierarchies of criteria by disintegrating a complex decision problem into several relevant components. The other advantage of using AHP as compared to other multi-criteria techniques is its capability to check inconsistencies and its intuitive appeal to decision makers [73]. Moreover, it supports group decision-making by developing consensus through computing the geometric mean of individual pairwise comparisons [74]. Furthermore, the results of AHP are more reliable and accurate than any other multivariate technique due to the mathematical foundation of this method [75]. In addition, hierarchy structure, complexity, unity, measurement, synthesis, interdependence, consistency, judgments and consensus, tradeoffs and process repetition are a few advantages of AHP over other multi-criteria decision-making techniques [70]. It is important to highlight that in most of the cases, AHP focuses on the best possible decision which proves to be the most adequate based on the user's requirements [76].Therefore, the AHP method is recommended for this work due to its reliability, consensus, process repetition, accuracy, and superiority in judgment and measuring scales over other multi-criteria techniques [75, 77-79]. 


\section{b) Procedure}

In the simplest arrangement, AHP can be utilized in decision-making. It is a three-level hierarchy as illustrated in Fig. 3. This hierarchy schema helps decision makerswith the decomposition of complex systems. The overall decision objective or goal is at the topmost level, the criteria or categories by which the alternatives will be evaluated are at the intermediate level, and the available alternatives or options are at the lowest hierarchy level. The AHP technique comprises four main steps (further details regarding the AHP can be obtained from [66, 67, 80, 81]).

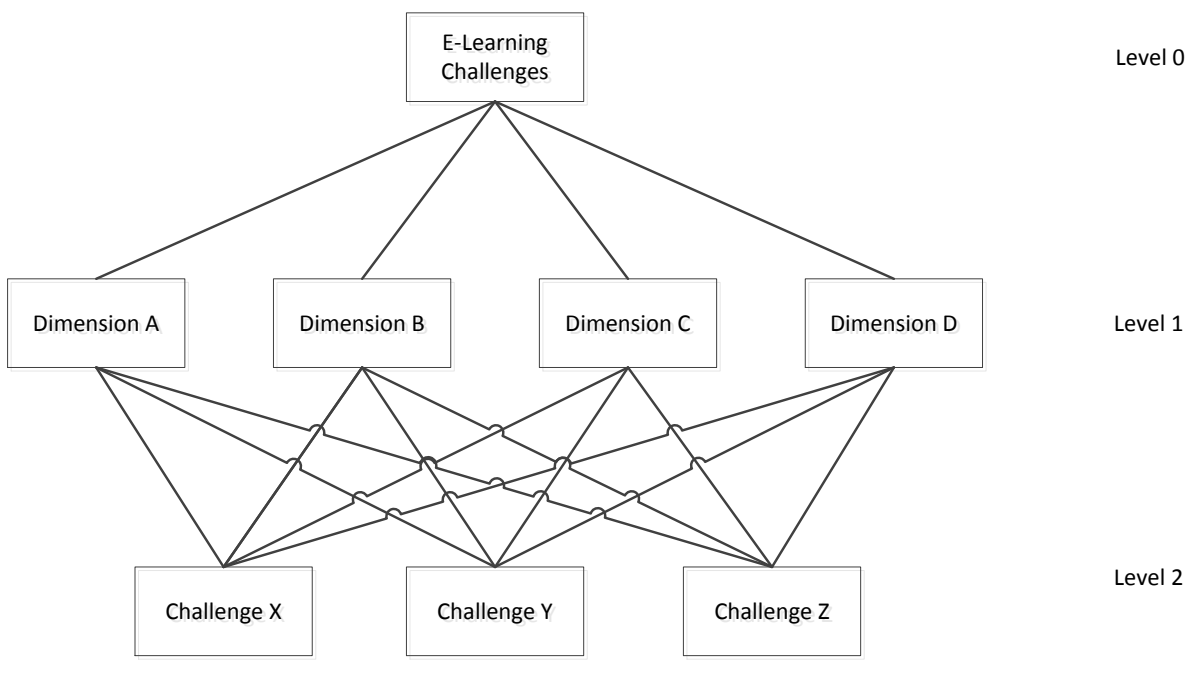

Fig 3: A systematic three-level decision making

\section{1) Constructing a Decision Problem}

The decision problem is broken down into a hierarchy consisting of three levels of interrelated decision elements that describe the problem. In order to determine the degree of importance associated with e-learning challenges, the problems can be decomposed into sub-problems within the hierarchy structure. The topmost level with only one element is the goal or objective to achieve, and the elements at the lowest level are the options or choices (challenges here). Elements at the intermediate level are the criteria or categories (dimensions here) for evaluating those options. In this work, the hierarchy of all dimensions and challenges has been classified into three levels as illustrated in Fig. 4. Section 4 explains the details of Fig. 4.

\section{2) Priority Setting of Criteria by Pairwise Comparison (Weighting)}

The data must be collected by pairwise comparisons of former elements to establish relations within the structure using a nine-point weighting scale (Table 3). For each pair of elements, the decision maker is required to respond to a question such as, "is A more important than B?" 


\section{3) Pairwise Comparison of Options on Each Criterion (scoring)}

For each pair within each criterion, the better option is granted a higher score on the nine-point scale. Each score represents how well option "x" meets criterion "A". Afterwards, the scores are normalized and averaged. Saaty[81], urged that pairwise comparisons of elements are required and should either be homogenous or close with respect to the common attribute, otherwise substantial errors may occur in the measurement process.

\section{4) Calculating the Overall Relative Score for each Option}

In order to obtain an overall relative score for each option, the criterion weights are combined with the option scores to produce an overall score for each option. The degree to which the options fulfill the criteria is weighed with respect to the relative importance of the criteria. Finally, the priorities for all elements in the hierarchy as a whole are computed, once the judgments on all elements are complete.

AHP has been widely utilized in different disciplines over the last two decades [72] including medicine[82], fisheries [72], e-commerce [83], software engineering [84-87], information systems [63, 88] and e-learning [3, 5, 72, $79,89,90]$ in different contexts. A hierarchical model for the critical e-learning challenges of HEIs in Pakistan has been developed using the AHP method. The proposed model consists of three layers including the research objective, the dimensions, and e-learning challenges associated with each dimension. We have designed pair-wise comparison questions in line with[79]. The weight of each factor (challenge) was calculated by AHP software and Microsoft Excel 2010. It was recommended by [67] that a consistency ratio of less than or equal to 0.10 is acceptable. Responses that did not meet the consistency ratio were excluded.

Table 3: The Fundamental Scale for Pairwise Comparison

\begin{tabular}{|c|c|l|}
\hline Scale & Definition & \multicolumn{1}{c|}{ Explanation } \\
\hline $\mathbf{1}$ & Equal importance & Two elements contribute equally to the objective \\
\hline $\mathbf{3}$ & $\begin{array}{c}\text { Moderate } \\
\text { importance }\end{array}$ & $\begin{array}{l}\text { Experience and judgment slightly favor one element over } \\
\text { another }\end{array}$ \\
\hline $\mathbf{5}$ & Strong Importance & $\begin{array}{l}\text { Experience and judgment strongly favor one element over } \\
\text { another }\end{array}$ \\
\hline $\mathbf{7}$ & $\begin{array}{c}\text { Very strong } \\
\text { importance }\end{array}$ & $\begin{array}{l}\text { One element is favored very strongly over another, its } \\
\text { dominance is demonstrated in practice }\end{array}$ \\
\hline $\mathbf{9}$ & $\begin{array}{c}\text { Extreme } \\
\text { importance }\end{array}$ & $\begin{array}{l}\text { The evidence of favoring one element over another is of the } \\
\text { highest possible order of affirmation }\end{array}$ \\
\hline Note: $2,4,6,8$ can be used to express intermediate values \\
\hline
\end{tabular}

\subsection{RESULTS}

The results fromthe conducted survey are summarized in Table 4.The mean values were calculated for each factor and the factors were arranged in descending order with respect to their mean values. The cutoff value was calculated by taking the mean of max-mean (Table $4: 3.77$ ) and min-mean (Table $4: 2.40$ ) values to filter the list of identified challenges with respect to the localized environment. The cutoff value of 3.08 is used to identify the relevant challenges whose mean valuesare greater than, or equal to 3.08. The challenges with mean valuesbelow 3.08 are not considered crucial in the opinion of experts. The reduced list of challenges is further used for prioritization using the AHP method. 
Table 4: E-learning Challenges with Mean Values

\begin{tabular}{|c|c|c|c|c|c|c|c|}
\hline \multirow{2}{*}{ Challenges } & \multirow{2}{*}{ Responses } & \multicolumn{5}{|c|}{ Level of Agreement } & \multirow{2}{*}{ Mean } \\
\hline & & 5 & 4 & 3 & 2 & 1 & \\
\hline \multirow{2}{*}{ Power failure } & Frequency & 14 & 13 & 11 & 2 & 3 & \multirow{2}{*}{3.77} \\
\hline & $\%$ & 33 & 30 & 25 & 5 & 7 & \\
\hline \multirow{2}{*}{ Lack of resources } & Frequency & 10 & 20 & 6 & 5 & 2 & \multirow{2}{*}{3.72} \\
\hline & $\%$ & 23 & 46 & 14 & 12 & 5 & \\
\hline \multirow{2}{*}{ Lack ICT enabled teachers } & Frequency & 6 & 23 & 10 & 3 & 1 & \multirow{2}{*}{3.70} \\
\hline & $\%$ & 14 & 53 & 23 & 7 & 2 & \\
\hline \multirow{2}{*}{ Software interface design } & Frequency & 8 & 22 & 6 & 4 & 3 & \multirow{2}{*}{3.65} \\
\hline & $\%$ & 19 & 51 & 14 & 9 & 7 & \\
\hline \multirow{2}{*}{ Lack of SQA process } & Frequency & 8 & 23 & 3 & 7 & 2 & \multirow{2}{*}{3.65} \\
\hline & $\%$ & 19 & 53 & 7 & 16 & 5 & \\
\hline \multirow{2}{*}{ Lack of LOs in local language } & Frequency & 7 & 22 & 6 & 7 & 1 & \multirow{2}{*}{3.63} \\
\hline & $\%$ & 16 & 51 & 14 & 16 & 2 & \\
\hline \multirow{2}{*}{ Cost of mobile Internet } & Frequency & 4 & 24 & 11 & 3 & 1 & \multirow{2}{*}{3.63} \\
\hline & $\%$ & 9 & 56 & 25 & 7 & 2 & \\
\hline \multirow{2}{*}{ Literacy rate } & Frequency & 7 & 20 & 11 & 2 & 3 & \multirow{2}{*}{3.60} \\
\hline & $\%$ & 16 & 46 & 25 & 5 & 7 & \\
\hline & Frequency & 4 & 19 & 12 & 6 & 2 & \\
\hline Lack of faculty interest & $\%$ & 9 & 44 & 28 & 14 & 5 & 3.40 \\
\hline & Frequency & 5 & 15 & 17 & 4 & 2 & \\
\hline Socio-Cultural Norms & $\%$ & 12 & 35 & 39 & 9 & 5 & 3.40 \\
\hline I ack of ICT enabled students. & Frequency & 5 & 13 & 19 & 5 & 1 & \\
\hline Lack of IC T enabled students & $\%$ & 12 & 30 & 44 & 12 & 2 & 3.37 \\
\hline & Frequency & 2 & 14 & 24 & 3 & 0 & \\
\hline Lack of instructional design processes & $\%$ & 5 & 33 & 56 & 7 & 0 & 3.35 \\
\hline & Frequency & 6 & 19 & 6 & 8 & 4 & \\
\hline Accessibility to Internet broadband & $\%$ & 14 & 44 & 14 & 19 & 9 & 3.35 \\
\hline & Frequency & 4 & 15 & 17 & 6 & 1 & \\
\hline Borrowed e-learning models & $\%$ & 9 & 35 & 39 & 14 & 2 & 3.35 \\
\hline & Frequency & 3 & 18 & 14 & 6 & 2 & \\
\hline Bandwidth & $\%$ & 7 & 42 & 33 & 14 & 5 & 3.33 \\
\hline & Frequency & 1 & 18 & 18 & 6 & 0 & \\
\hline Lack of formal implementation processes & $\%$ & 5 & 42 & 42 & 14 & 0 & 3.33 \\
\hline & Frequency & 3 & 16 & 12 & 7 & 5 & \\
\hline Practical arrangements & $\%$ & 7 & 37 & 28 & 16 & 12 & 3.12 \\
\hline Learning stvle & Frequency & 5 & 13 & 3 & 20 & 2 & \\
\hline Learning styıe & $\%$ & 12 & 30 & 7 & 46 & 5 & 2.98 \\
\hline & Frequency & 4 & 9 & 11 & 16 & 3 & \\
\hline Access to the latest computers & $\%$ & 9 & 21 & 25 & 37 & 7 & 2.88 \\
\hline & Frequency & 2 & 13 & 15 & 4 & 9 & \\
\hline Lack of instructional designers & $\%$ & 5 & 30 & 35 & 9 & & 2.88 \\
\hline & Frequency & 4 & 5 & 18 & 13 & 3 & \\
\hline E-learning environment & $\%$ & 9 & 12 & 42 & 30 & 7 & 2.86 \\
\hline & Frequency & 4 & 6 & 15 & 16 & 2 & \\
\hline Role of teachers and students & $\%$ & 9 & 14 & 35 & 37 & 5 & 2.86 \\
\hline & Frequency & 1 & 7 & 15 & 18 & 3 & \\
\hline Support for students & $\%$ & 2 & 16 & 35 & 42 & 7 & 2.63 \\
\hline & Frequency & 2 & 2 & 26 & 3 & 10 & \\
\hline Change in university structure & $\%$ & 5 & 5 & 60 & 7 & 23 & 2.60 \\
\hline Support for teachers & Frequency & 2 & 7 & 10 & 16 & 8 & 2.51 \\
\hline
\end{tabular}




\begin{tabular}{|l|c|c|c|c|c|c|c|}
\hline & $\%$ & 5 & 16 & 23 & 37 & 19 & \\
\hline \multirow{2}{*}{ Lack of leadership } & Frequency & 6 & 1 & 11 & 11 & 14 & \multirow{2}{*}{2.40} \\
\cline { 2 - 8 } & $\%$ & 14 & 2 & 25 & 25 & 33 & \\
\hline
\end{tabular}

Data were collected by sending AHP questionnaires (an example is given in the Appendix) to the target e-learning experts. Forty-seven participants responded, for a response rate of $92 \%$. Three of the responses were removed due to high inconsistency ratio; the remaining (forty-four) respondents reached the consistency ratio. Table 5 illustrates that the software dimension (0.5020) emerged as the most important dimension to the promotion of e-learning in Pakistani HEIs. However,respondents gave the personal dimension (0.0320) the least importance for the implementation of e-learning. The overall weights and ranking of the dimensions are illustrated in Table 5.

Table 5:AHP weights and dimension rankings

\begin{tabular}{lccc}
\hline & Dimensions & Weights & Ranking \\
\hline Software & & 0.5020 & 1 \\
Technical & 0.1050 & 3 \\
Institutional & 0.2310 & 2 \\
Personal & 0.0320 & 5 \\
Cultural & 0.1310 & 4 \\
\hline
\end{tabular}

Table 6: AHP Local Weights and Ranks of E-Learning Challenges

\begin{tabular}{lcc}
\hline \multicolumn{1}{c}{ Challenges } & Weights (Local) & Rank (Local) \\
\hline Software interface design & 0.4670 & 1 \\
Lack of ID Processes & 0.0670 & 3 \\
Lack of SQA processes & 0.4670 & 2 \\
Bandwidth & 0.0920 & 4 \\
Accessibility toInternet broadband & 0.1050 & 3 \\
Cost of mobile Internet & 0.1290 & 2 \\
Power failure & 0.6740 & 1 \\
Practical arrangement for practical oriented courses & 0.0370 & 4 \\
Lack of resources & 0.3800 & 2 \\
Lack of formal implementation processes & 0.1860 & 3 \\
Borrowed e-learning models & 0.3970 & 1 \\
Lack of faculty interest & 0.7690 & 1 \\
Lack of ICT enabled teachers & 0.1040 & 3 \\
Lack of ICT enabled students & 0.1270 & 2 \\
Lack of LOs in the local language & 0.1110 & 2 \\
Socio-cultural norms & 0.1110 & 3 \\
Literacy rate & 0.7780 & 1 \\
\hline
\end{tabular}

The local weights of each critical challenge along with the associated ranks of the respective dimensions are depicted in Table 6. The global weight of each critical challenge along with the related ranks is illustrated in Table 7. Software interface design (0.234434), is lacking of software quality assurance processes $(0.234434)$, literacy rate (0.101918), bandwidth (0.096600) and borrowed e-learning model (0.091707) are considered the top five influential challenges in the promotion of e-learning in HEIs in Pakistan. 
Table 7: AHP Global Weights and Ranks Of E-Learning Challenges

\begin{tabular}{lcc}
\hline \multicolumn{1}{c}{ Challenges } & Weights (Global) & Rank (Global) \\
\hline Software Interface design & 0.234434 & 1 \\
Lack of SQA processes & 0.234434 & 2 \\
Literacy rate & 0.101918 & 3 \\
Bandwidth & 0.096600 & 4 \\
Borrowed e-learning models & 0.091707 & 5 \\
Lack of resources & 0.087780 & 6 \\
Power failure & 0.070770 & 7 \\
Lack of formal implementation processes & 0.042966 & 8 \\
Lack of ID Processes & 0.033634 & 9 \\
Lack of faculty interest & 0.024608 & 10 \\
Lack of LOs in the local language & 0.014541 & 11 \\
Socio-cultural norms & 0.014541 & 12 \\
Cost of mobile Internet & 0.013545 & 13 \\
Accessibility toInternet broadband & 0.011025 & 14 \\
Practical arrangement for practical oriented courses & 0.008547 & 15 \\
Lack of ICT enabled students & 0.004064 & 16 \\
Lack of ICT enabled teachers & 0.003328 & 17 \\
\hline
\end{tabular}

\subsection{DISCUSSION AND IMPLICATIONS}

In this section, the identified dimensions and study implications for researchers and practitioners of e-learning are discussed. Moreover, some of the limitations are also discussed at the end of this section.

\subsection{Discussion}

On the basis of our data collection (survey and literature review), a hierarchal model was developed based on AHP for the e-learning challenges (Fig. 4). The findings revealed that major stakeholders of e-learning systems are faced with at least seventeen crucial challenges from five dimensions, which influence the implementation and promotion of e-learning in the country. These dimensions include software, technical, institutional, personal and cultural. The emergence of five dimensions is significant, as this is consistent with state-of-the-art e-learning literature, which reportsa similar number of dimensions in different contexts of e-learning[5, 9, 20, 91-93].Each dimension is discussed separately below.

\section{a) Software}

Based on the information gainedfrom literature review, the Software dimension has emerged as one of the important dimension that deals with the development ofe-learning products or learning objects (LOs). An e-learning product is a piece of software developed for learning purposes, such as small simulations, static htmlpages, power point slides or online courses[30,94]. The software dimension also addresses the development of e-learning platforms that could serve as LMS or CMS. It has also been observed that the development process of an e-learning product has many similarities with the software development process[39]. Moreover, the process model used to develop an e-learning product is identical to the traditionalWater Fall Software Development Process Model[95]. The perceived challenges,such as lack of quality assurance processes for e-products, lack of instructional design processes and poor software interfaces are influential on software engineering or the software development discipline. Hence, these challenges are grouped in the software category. 


\section{b) Technical}

The integration of ICT in education has raised many challenges for HEIs and learners. One of the common challenges regarding the technical category is accessibility to technology for learners to attain knowledge and information[45, 57].

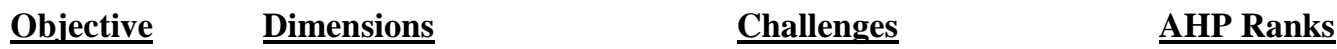

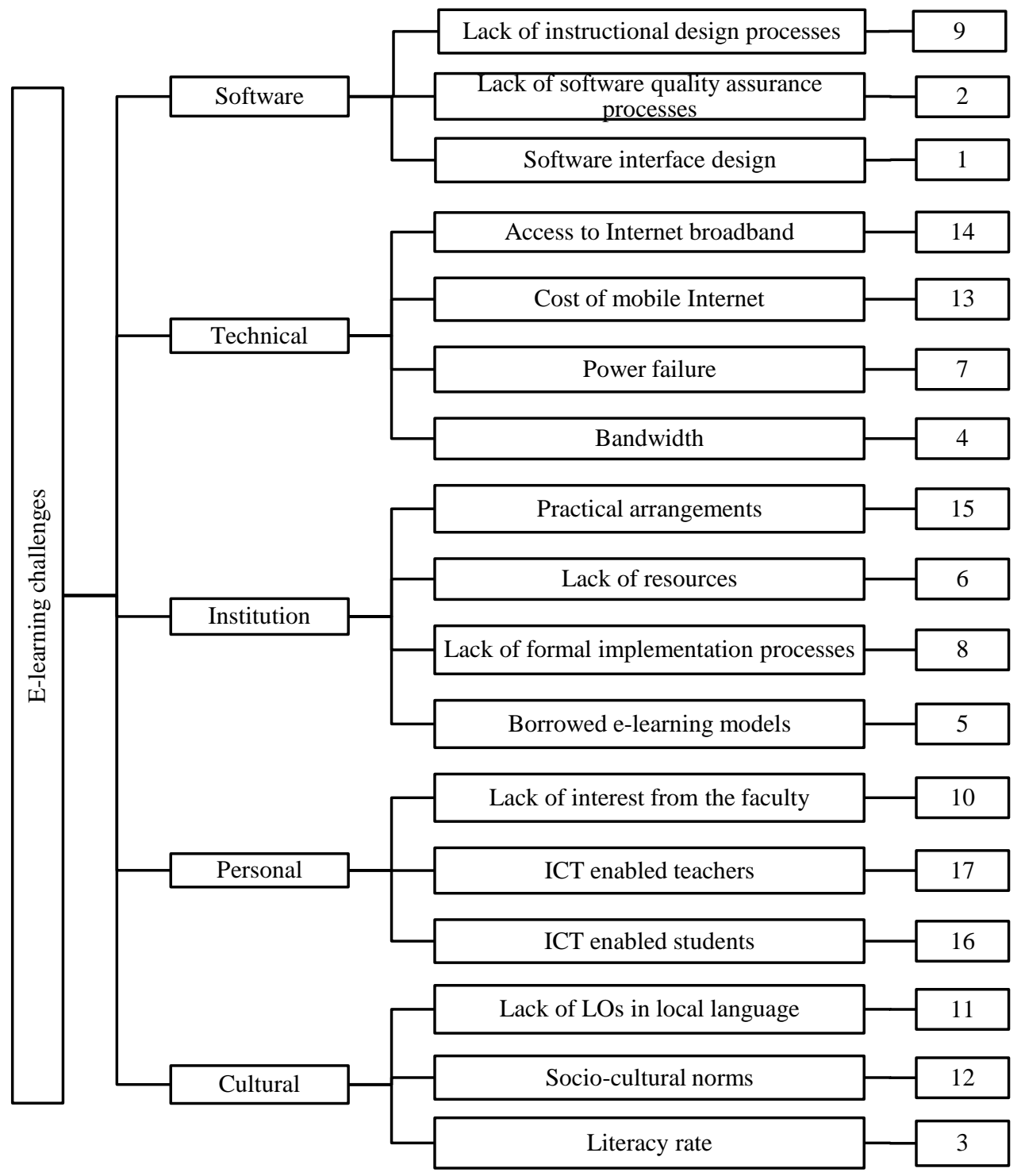

Fig. 4: Hierarchical model of e-learning challenges 
Accessibility to technology includes access to sufficient bandwidth [43], high-speed Internet broadband [96] and the cost of accessing these technologies. Beside all these challenges, the most important and major challenge is the steady supply of electric power. The successful implication and execution of e-learning require un-interrupted supply of electric power, as nearly all communication equipment needs continuous and steady power supply to operate. Hence, the challenges related to ICT, like bandwidth, Internet broadband, mobile Internet, the latest computers, power failure and the cost of accessing these technologies are grouped in the technical dimension.

\section{c) Institution}

Institutional visions, long-term aims, established procedures, standards and e-learning models are necessary for the successful implementation of e-learning systems. It depends on the HEI's policies and how they utilise existing resources for the successful implementation and execution of e-learning systems[46]. Most often, developing countries adopt e-learning models, tools or technologies from developed countries [14, 54]. The challenges faced by HEIs in developing countries with implementing and promoting e-learning are different from those in developed countries [5]. The requirements of organizations vary from one another, and consequently, one model is not suitable for all due to environmental and cultural differences. Hence, it is required for HEIs to formulate localized standards in order to promote e-learning in their countries. The challenges with lack of resources, practical arrangements for practical oriented courses, and lack of formal implementation processes are related to the institutions providing elearning facilities and hence are grouped in the institution dimension.

\section{d) Personal}

The interest and willingness of faculty members and learners is deemed a prime factor in the success of teaching and learning. HEIs are facing an extreme shortage of ICT enabled teachers and learners. The lack of ICT skills is one of the challenges with e-learning adoption and promotion[47, 97, 98]. Faculty members of formal public sector universities are not keen on developing the e-learning environment. Moreover, shifting from traditional teaching environment to an e-learning environment is difficult for both teachers and learners, as they are accustomed and comfortable with traditional teaching environments[99]. In addition, e-learning shifts from teaching-centered to learner-centered, and challenged the traditional concept of learning, in which the teacher plays an active role in education. Traditionalists cannot support e-learning, as it goes against their basic educational assumptions[11]. The issues associated with learners and teachers are placed in the personal dimension.

\section{e) Cultural}

It is crucial to consider the impact of culture and social issues before integrating ICT in education [17]. Approximately $40 \%$ of the total population is younger than 19, which indicates that Pakistan has relatively young human resources. More than 300 different languages are spoken in the various regions of Pakistan, but English has been adopted as an official language for education, industry and commerce [100]. According to Pakistan Social and Living Standards Measurement's latest survey (2012-13), the overall literacy rate of the population (10 years old and above) was $60 \%$, which is $2 \%$ higher than the previous year [101]. People from remote areas particularly the provinces of Baluchistan, KPK and Gilgit-Baltistan,are not keen onlocal females moving to urban areas for the sake of education due to cultural and social constraints. Moreover, the education of females in these areas is banned on the basis of religion [102]. Moreover, HEIs in developed countries have been coming up with e-products for the last 3 decades. These products are later adopted by developing countries[30], but due to lower literacy rates and lack of e-products in local languages, learners are hesitant to enroll in e-learning courses. The language barrier difficulty is also reported in literature [14, 38, 42, 103]. Challenges like socio-cultural norms, literacy rate and lack of LOs in local languages are associated with cultural norms of Pakistan, hence are grouped in the cultural dimension. 


\subsection{Implications for Research and Practice}

The research furnishes various implications ofe-learning system implementation and promotion in Pakistan. Policy makers and monitoring authorities of Pakistan (HEC and ICT R\&D Fund) should adopt the given implementation strategies to achieve the GOP target, i.e. "education for all" and to accelerate the paradigm shift process. HEC has already assisted all public sector universities by providing video conferencing systems to promote e-learning. But still there are needs to (a) enhance the existing ICT infrastructure that links all public and private sector universities; (b) increase the Internet broadband capacity to reap maximum benefits from this facility; (c) provide sufficient funds to support HEIs in adopting an e-learning mode of education; (d) devise a localized e-learning model for HEIs and (e) develop a unique e-learning implementation roadmap, which should be strictly followed by HEIs.

On the other hand, HEIs are required to motivate faculty members to accept e-learning as a new paradigm by conducting seminars and workshops on the advantages of e-learning. HEIs should: (a) provide computer training to faculty members so they can motivate learners to enroll into e-learning; (b) provide escalated computer usage among students and teachers; (c) launch technology awareness and training to related stakeholders; (d) motivate to increase student intake by providing various incentives for e-learning adoption; and (e) offer additional courses related to elearning.

\subsection{Limitations}

There are certain limitations regarding the challenges of implementing e-learning in developing countries like Pakistan. This researchfocused only on three stakeholders in e-learning systems, which are academicians, administrators and software developers. Further investigations are recommended to consider other stakeholders of elearning systems, such as learners, instructional designers, online facilitators, LO developers and multimedia designers. This study limited the participants to one country, Pakistan.Nonetheless, this work can be enhanced by including participants from other developing countries like Malaysia, India, Bangladesh, and Sri Lanka. On the other hand, Pakistan represents a developing country and encounters similar challenges as other developing countries. Hence, the proposed model can be utilized to identify existing or emerging challenges faced by HEIs in other developing countries, and prioritizing the challenges by adding or withdrawing issues or challenges associated with localized requirements.

\subsection{CONCLUSIONS AND FUTURE WORK}

E-learning is becoming the new driving force behind learning and training. Over the last decade, e-learning has rapidly been gaining importance in industry and academia owing to its flexible mode of learning. However, it is not gaining as much attention as expected due to lessICT exposure in developing countries like Pakistan. Moreover, most HEIs in developing countries are encountering various challenges that are unique compared to developed countries. These challenges make it difficult to shift to the new paradigm of learning and training.It was found in the current study that the most important challenges affecting e-learning implementation relate to the enhancement of basic ICT skills of learners and instructors, providing technological awareness opportunities and educating people,particularly from KPK province, to accept female enrollment in e-learning programs. Moreover, it was also perceived that the quality assurance of e-learning systems, poorly designed e-learning platform software interfaces, as well as lack of implementation processes,development of localized learning objects, socio-cultural norms and literacy, hinders the implementation of this model. In essence, this study was conducted to discover a comprehensive set of critical barriers specific to developing countries and that are creating problems in the successful implementation of e-learning. The main contribution of this work is a hierarchal model constituting the challenges encountered by various stakeholders with e-learning systems in shifting from traditional to lifelong learning environments. The recognized challenges generate doubt to the implementation and promotion of lifelong paradigm. This study revealed 17 challenges that act as hurdles in the integration of ICT into education at HEIs in 
Pakistan. A hierarchy of the identified challenges was devised by deploying AHP with respect to their significance to localized environment. These challenges necessitate immediate attention by government agencies dealing with higher education. The significance of a successful e-learning system can only be achieved when related issues are fully measured and resolved. A novel educational policy needs formulation in order to achieve the paradigm shift. Higher education institutions must understand and evaluate the factors driving learners and teachers towards a successful e-learning system.

This empirical study is apromising approach in the direction of identifyingcritical challenges as well as the implementation of e-learning in developing countries. Future research may consider the identification of challenges for the implementation of cloud-based e-learning, the development of quality assurance mechanisms for e-learning systems, the development of LO process models and the significance of outsourcing localized LO.

\section{REFERENCES}

[1] P. Gerbic, "What about flexible learning and ICT?-A review of technology based flexible learning in tertiary education," in Third Pan-Commonwealth Forum Conference, 4-8 July 2004, 2004.

[2] P. Sajja, "Enhancing quality in e-Learning by knowledge-based IT support," International Journal of Education and Development using ICT, vol. 4, 2008.

[3] M. S. Abdellatief, A.B.M. Jabar, M.A. Abdullah, R., "A Technique for Quality Evaluation of E-Learning from Developers Perspective," American Journal of Economics and Business Administration, vol. 3, pp. 157-164, 2011.

[4] B. Collis and J. Moonen, Flexible learning in a digital world: Experiences and expectations: Routledge, 2012.

[5] W. Bhuasiri, O. Xaymoungkhoun, H. Zo, J. J. Rho, and A. P. Ciganek, "Critical success factors for elearning in developing countries: A comparative analysis between ICT experts and faculty," Computers \& Education, vol. 58, pp. 843-855, 2012.

[6] C. Latchem, "Towards borderless virtual learning in higher education," Global perspectives on e-learning: rhetoric and reality, pp. 179-198, 2005.

[7] D. French, Internet based learning: An introduction and framework for higher education and business: Stylus Pub Llc, 1999.

[8] B. H. Khan, "The global e-learning framework," STRIDE, p. 42, 2003.

[9] H. M. Selim, "Critical success factors for e-learning acceptance: Confirmatory factor models," Computers \& Education, vol. 49, pp. 396-413, 2007.

[10] G. Puri, "Critical success Factors in e-Learning-An empirical study," International Journal of Multidisciplinary Research, vol. 2, pp. 149-161, 2012.

[11] D. Forman, L. Nyatanga, and T. Rich, "E-learning and educational diversity," Nurse Education Today, vol. 22, pp. 76-82, 2002. 
[12] P.-C. Sun, R. J. Tsai, G. Finger, Y.-Y. Chen, and D. Yeh, "What drives a successful e-Learning? An empirical investigation of the critical factors influencing learner satisfaction," Computers \& Education, vol. 50, pp. 1183-1202, 2008.

[13] Å. Grönlund and Y. M. Islam, "A mobile e-learning environment for developing countries: The Bangladesh virtual interactive classroom," Information Technology for Development, vol. 16, pp. 244-259, 2010.

[14] A. Nawaz, "E-Learning experiences of HEIs in advanced states, developing countries and Pakistan," Universal Journal of Education and General Studies, vol. 1, pp. 72-83, 2012.

[15] A. Khan, "The Education System and Prospects for e-learning in Pakistan," End-to-End eLearning, Stockholm College, Stockholm, 2007.

[16] M. J. Iqbal and M. Ahmed, "Enhancing quality of education through e-learning: the case study of Allama Iqbal Open University," The Turkish Online Journal of Distance Education, vol. 11, 2010.

[17] I. A. Qureshi, K. Ilyas, R. Yasmin, and M. Whitty, "Challenges of implementing e-learning in a Pakistani university," Knowledge Management \& E-Learning: An International Journal (KM\&EL), vol. 4, pp. 310324, 2012.

[18] S. Farid, R. Ahmad, I. Niaz, J. Itmazi, and K. Asghar, "Identifying Perceived Challenges of E-Learning Implementation," presented at the First International Conference on Modern Communication \& Computing Technologies (MCCT'14), Nawabshah, Pakistan, 2014.

[19] Q. A. Qureshi, A. Nawaz, and N. Khan, "Prediction of the problems, user-satisfaction and prospects of elearning in HEIs of KPK, Pakistan," International Journal of Science and Technology Education Research, vol. 2, pp. 13-21, 2011.

[20] S. Farid, R. Ahmad, I. A. Niaz, M. Arif, S. Shamsherband, and M. Daud Khattak, "Identification and prioritization of critical issues for the promotion of e-learning in Pakistan," Computers in Human Behavior vol. 51, pp. 161-171, 2015.

[21] S. Gulati, "Technology-enhanced learning in developing nations: A review," The International Review of Research in Open and Distance Learning, vol. 9, 2008.

[22] M. T. Islam and A. S. M. Selim, "Current status and prospects for e-learning in the promotion of distance education in Bangladesh," Turkish Online Journal of Distance Education, vol. 7, pp. 114-119, 2006.

[23] H. D. Perraton, Open and distance learning in the developing world: Routledge, 2007.

[24] A. Sife, E. Lwoga, and C. Sanga, "New technologies for teaching and learning: Challenges for higher learning institutions in developing countries," International Journal of Education and Development using ICT, vol. 3, 2007.

[25] P. Pagram and J. Pagram, "Issues in e-learning: A Thai case study," The Electronic Journal of Information Systems in Developing Countries, vol. 26, 2006.

[26] L. Olsina, G. Lafuente, and G. Rossi, "Specifying quality characteristics and attributes for websites," in Web Engineering, ed: Springer, 2001, pp. 266-278. 
[27] S. G. Sanjay Kumar Dubey, Prof. (Dr.) Ajay Rana, "Comparison of Software Quality Models: An Analytical Approach," International journal of Emerging Technology and Advanced Engineering, vol. 2, pp. 111-119, 2012.

[28] F. Kanwal and M. Rehman, "E-learning Adoption Model: A case study of Pakistan," Life Science Journal, vol. 11, 2014.

[29] HEC. (2013, 14.07.2014). Higher Education Commission, Pakistan. Available: http://www.hec.gov.pk/InsideHEC/Divisions/eReforms/Pages/Main.aspx

[30] D. Khattak, "Development of Multimedia Instruction Objects for Delivery in a Localized E-Learning Environment," Ph.D., Computer Science Department, Allama Iqbal Open University, Islamabad, Pakistan, 2010.

[31] A. Zafar and S. H. Hasan, "A NOVEL SCHEME FOR INFORMATION RETRIEVAL FROM ELEARNING REPOSITORY," Malaysian Journal of Computer Science, vol. 28, p. 1, 2015.

[32] Ç. GÜLER and A. Altun, "Teacher trainees as learning object designers: Problems and issues in learning object development process," TOJET, vol. 9, 2010.

[33] R. W. Lau, N. Y. Yen, F. Li, and B. Wah, "Recent development in multimedia e-learning technologies," World Wide Web, pp. 1-10, 2013.

[34] Z. H. Siddiqui, "Promoting E-Learning in Pakistan: Strategies and Challenges," in Paper Presented e-Asia Conference and Exhibition Putrajaya Malaysia, 2007.

[35] G. M. Kundi, A. Nawaz, and S. Khan, "The predictors of success for e-learning in higher education institutions (HEIs) in NW. FP, Pakistan," JISTEM-Journal of Information Systems and Technology Management, vol. 7, pp. 545-578, 2010.

[36] F. Hasson, S. Keeney, and H. McKenna, "Research guidelines for the Delphi survey technique," Journal of advanced nursing, vol. 32, pp. 1008-1015, 2000.

[37] T. Ivergård and B. Hunt, "Towards a learning networked organisation: human capital, compatibility and usability in e-learning systems," Applied ergonomics, vol. 36, pp. 157-164, 2005.

[38] K. Shraim and Z. Khlaif, "An e-learning approach to secondary education in Palestine: opportunities and challenges," Information Technology for Development, vol. 16, pp. 159-173, 2010.

[39] E. F. Barbosa and J. C. Maldonado, "Towards the establishment of a standard process for developing educational modules," in Frontiers in Education Conference, 36th Annual, 2006, pp. 5-10.

[40] B. B. Chua and L. E. Dyson, "Applying the ISO 9126 model to the evaluation of an elearning system," in Proc. of ASCILITE, 2004, pp. 5-8.

[41] N. S. C. Babu, "Quality Assurance Framework for e-Learning," ELEL Tech, India, 2005.

[42] A. Anuwar and T. S. Datuk, "Issues and challenges in implementing e-learning in Malaysia," 2004.

[43] G. Homan and A. Macpherson, "E-learning in the corporate university," Journal of European Industrial Training, vol. 29, pp. 75-90, 2005. 
[44] M. Kamba, "Problems, challenges and benefits of implementing e-learning in Nigerian universities: An empirical study," International Journal of Emerging Technologies in Learning (iJET), vol. 4, 2009.

[45] J. Mapuva, "Confronting challenges to e-learning in Higher Education Institutions," International Journal of Education and Development Using ICT, vol. 5, pp. 101-114, 2009.

[46] D. Masoumi and B. Lindström, "Quality in e-learning: a framework for promoting and assuring quality in virtual institutions," Journal of Computer Assisted Learning, vol. 28, pp. 27-41, 2012.

[47] J. Carr, "The role of higher education in the effective delivery of multimedia management training to small and medium-sized enterprises," Educational Technology \& Society, vol. 2, pp. 1-15, 1999.

[48] S. Levy, "Six factors to consider when planning online distance learning programs in higher education," Online Journal of Distance Learning Administration, vol. 6, 2003.

[49] H. Põldoja, T. Väljataga, M. Laanpere, and K. Tammets, "Web-based self-and peer-assessment of teachers' digital competencies," World Wide Web, pp. 1-15, 2012.

[50] A. Nawaz and M. Z. Khan, "Issues of Technical Support for e-Learning Systems in Higher Education Institutions," International Journal of Modern Education and Computer Science (IJMECS), vol. 4, p. 38, 2012.

[51] R. Oliver, "Assuring the quality of online learning in Australian higher education," 2001.

[52] N. A. Sangi, "Electronic assessment issues and practices in Pakistan: a case study," Learning, Media and Technology, vol. 33, pp. 191-206, 2008.

[53] A. Andersson, "Seven major challenges for e-learning in developing countries: Case study eBIT, Sri Lanka," International Journal of Education and Development using ICT, vol. 4, 2008.

[54] H. M. A. N. Maher Alghali, I. Roesnita, "Challenges and Benefits of Implementing Cloud Based ELearning in Developing Countries," presented at the Proceeding of the Social Sciences Research ICSSR 2014, Kota Kinabalu,Sabah, MALAYSIA, 2014.

[55] T. Scott, "The wired campus," Business Weekly, vol. 102, 2000.

[56] L. Darling, "Your ELearning Strategy: Make sure it's learning for results," Training, vol. 39, p. 2, 2002.

[57] A. S. Andersson and Å. Grönlund, "A conceptual framework for e-learning in developing countries: A critical review of research challenges," The Electronic Journal of Information Systems in Developing Countries, vol. 38, 2009.

[58] J. Pallant, "SPSS survival manual: a step by step guide to data analysis using SPSS. England," ed: Open University Press, 2010.

[59] B. Williams, T. Brown, and A. Onsman, "Exploratory factor analysis: A five-step guide for novices," Australasian Journal of Paramedicine, vol. 8, p. 1, 2012.

[60] M. C. Tam and V. Tummala, "An application of the AHP in vendor selection of a telecommunications system," Omega, vol. 29, pp. 171-182, 2001. 
[61] V. G. Kaushik, Deepti, "Multivariate Factor Analysis A Method for Psychological Analysis," International Journal for Advance Research in Engineering and Technology, vol. 2, 2014.

[62] A. Vizcaíno, F. García, J. C. Villar, M. Piattini, and J. Portillo, "Applying Q-methodology to analyse the success factors in GSD," Information and Software Technology, vol. 55, pp. 1200-1211, 2013.

[63] J. L. Salmeron and I. Herrero, "An AHP-based methodology to rank critical success factors of executive information systems," Computer Standards \& Interfaces, vol. 28, pp. 1-12, 2005.

[64] C. Y. Chong, S. P. Lee, and T. C. Ling, "Prioritizing and fulfilling quality attributes for virtual lab development through application of fuzzy analytic hierarchy process and software development guidelines," Malaysian Journal of Computer Science, vol. 27, 2014.

[65] L. Rodriguez-Repiso, R. Setchi, and J. L. Salmeron, "Modelling IT projects success: Emerging methodologies reviewed," Technovation, vol. 27, pp. 582-594, 2007.

[66] T. L. Saaty, "A scaling method for priorities in hierarchical structures," Journal of mathematical psychology, vol. 15, pp. 234-281, 1977.

[67] T. L. Saaty, "The analytic hierarchy process: planning, priority setting, resources allocation," M cGrawHill, 1980.

[68] C. Macharis, J. Springael, K. De Brucker, and A. Verbeke, "PROMETHEE and AHP: The design of operational synergies in multicriteria analysis.: Strengthening PROMETHEE with ideas of AHP," European Journal of Operational Research, vol. 153, pp. 307-317, 2004.

[69] F. Zahedi, "The analytic hierarchy process-a survey of the method and its applications," interfaces, vol. 16, pp. 96-108, 1986.

[70] T. Lirn, H. Thanopoulou, M. J. Beynon, and A. K. C. Beresford, "An application of AHP on transhipment port selection: a global perspective," Maritime Economics \& Logistics, vol. 6, pp. 70-91, 2004.

[71] G. A. Forgionne, R. Kohli, and D. Jennings, "An AHP analysis of quality in AI and DSS journals," Omega, vol. 30, pp. 171-183, 2002.

[72] S. Mardle, S. Pascoe, and I. Herrero, "Management objective importance in fisheries: an evaluation using the analytic hierarchy process (AHP)," Environmental Management, vol. 33, pp. 1-11, 2004.

[73] R. Ramanathan, "A note on the use of the analytic hierarchy process for environmental impact assessment," Journal of Environmental Management, vol. 63, pp. 27-35, 2001.

[74] S. Zahir, "Clusters in a group: Decision making in the vector space formulation of the analytic hierarchy process," European Journal of Operational Research, vol. 112, pp. 620-634, 1999.

[75] M. Dabbagh and S. P. Lee, "A consistent approach for prioritizing system quality attributes," in Software Engineering, Artificial Intelligence, Networking and Parallel/Distributed Computing (SNPD), 2013 14th ACIS International Conference on, 2013, pp. 317-322.

[76] S. M. Tofighy, R. G. Raj, and H. H. S. Javadi, "AHP techniques for Persian text summarization," Malaysian Journal of Computer Science, vol. 26, pp. 1-8, 2013. 
[77] E. F. Lane and W. A. Verdini, "A consistency test for AHP decision makers," Decision Sciences, vol. 20, pp. 575-590, 1989.

[78] E. H. Forman, "AHP is intended for more than expected value calculations," Decision Sciences, vol. 21, pp. 670-672, 1990.

[79] D. Y. Shee and Y. S. Wang, "Multi-criteria evaluation of the web-based e-learning system: A methodology based on learner satisfaction and its applications," Computers \& Education, vol. 50, pp. 894-905, 2008.

[80] T. L. Saaty, Fundamentals of decision making and priority theory with the analytic hierarchy process vol. 6: Rws Publications, 2000.

[81] T. L. Saaty, "How to make a decision: the analytic hierarchy process," European journal of operational research, vol. 48, pp. 9-26, 1990.

[82] L.-A. Vidal, E. Sahin, N. Martelli, M. Berhoune, and B. Bonan, "Applying AHP to select drugs to be produced by anticipation in a chemotherapy compounding unit," Expert Systems with Applications, vol. 37, pp. 1528-1534, 2010.

[83] C.-H. Hsu, C.-M. Yang, T.-C. Chen, and C.-Y. Chen, "Applying AHP method select online shopping platform," in Service Systems and Service Management (ICSSSM), 2010 7th International Conference on, 2010, pp. 1-5.

[84] M. Dabbagh and S. P. Lee, "An Approach for Integrating the Prioritization of Functional and Nonfunctional Requirements," The Scientific World Journal, vol. 2014, 2014.

[85] R. L. Armacost, P. J. Componation, M. A. Mullens, and W. W. Swart, "An AHP framework for prioritizing customer requirements in QFD: an industrialized housing application," IIE transactions, vol. 26, pp. 72-79, 1994.

[86] J.-S. Chou, "Applying AHP-based CBR to estimate pavement maintenance cost," Tsinghua Science \& Technology, vol. 13, pp. 114-120, 2008.

[87] J. Kontio, "A case study in applying a systematic method for COTS selection," in Software Engineering, 1996., Proceedings of the 18th International Conference on, 1996, pp. 201-209.

[88] M.-K. Chen and S.-C. Wang, "The critical factors of success for information service industry in developing international market: Using analytic hierarchy process (AHP) approach," Expert Systems with Applications, vol. 37, pp. 694-704, 2010.

[89] B. Behkamal, M. Kahani, and M. K. Akbari, "Customizing ISO 9126 quality model for evaluation of B2B applications," Information and software technology, vol. 51, pp. 599-609, 2009.

[90] F. Colace, M. De Santo, and A. Pietrosanto, "Evaluation models for e-learning platform: an AHP approach," in Frontiers in Education Conference, 36th Annual, 2006, pp. 1-6.

[91] O. Isik, "E-learning Satisfaction Factors," in Proceedings of the 39th Annual Meeting of the Decision Sciences Institute, Baltimore, 2008, pp. 941-946.

[92] D. E. Leidner and S. L. Jarvenpaa, "The information age confronts education: Case studies on electronic classrooms," Information Systems Research, vol. 4, pp. 24-54, 1993. 
[93] C. L. Dillon and C. N. Gunawardena, "A framework for the evaluation of telecommunications-based distance education," in Selected papers from the 17th world congress of the International Council for Distance Education, 1995, pp. 348-351.

[94] T. Berger and U. Rockmann, "Quality of e-learning products," in Handbook on Quality and Standardisation in E-Learning, ed: Springer, 2006, pp. 143-155.

[95] P. Punyabukkana, B. Sowanwanichakul, and A. Suchato, "RELAD: A Rapid eLearning Authoring and Development Model," in Third International Conference on eLearning for Knowledge-Based Society, 2006.

[96] R. Mason and F. Rennie, "Broadband: A solution for rural e-Learning?," The International Review of Research in Open and Distance Learning, vol. 5, 2004.

[97] D. Watson, "Understanding the relationship between ICT and education means exploring innovation and change," Education and Information Technologies, vol. 11, pp. 199-216, 2006.

[98] K. Croxall and M. N. Cummings, "Computer usage in family and consumer sciences classrooms," Journal of Family and Consumer Sciences Education, vol. 18, pp. 9-18, 2000.

[99] D. Wong, "A critical literature review on e-learning limitations," Journal for the Advancement of Science \& Arts. School of Management \& Information Technology, UCSI. Carseland, 2007.

[100] Unicef, "Pakistan: Statistics," ed, 2011.

[101] M. o. Finance, "Pakistan Economic Survey 2013-14," ed, 2014.

[102] A. Latif, "Alarming situation of education in Pakistan," Press International Report, 2011.

[103] J. Hvorecký, V. Manažmentu, and P. Cesta, "Can E-learning break the Digital Divide," European Journal of Open, Distance and E-Learning. Retrieved April, vol. 10, p. 2007, 2005. 